\title{
Hubungan Tingkat Pengetahuan Perawat Dalam Promosi dan Evaluasi Penerapan Budaya Keselamatan Pasien
}

\author{
Riana Silvia Casuarina L.Tobing \\ riana.sct@gmail.com
}

\section{Latar Belakang :}

Budaya kesclamatan pasien adalah produk dari nilai, sikap, kompetensi dan pola perilaku individu dan kelompok yang menentukan komitmen, gaya dan kemampuan organisasi pelayanan keschatan terhadap program keselamatan pasien (Kemenkes, 2017). Dimensi dalam budaya keselamatan pasicen yaitu (Sorra et al. 2016): keterbukaan komunikasi, umpan balik dan komunikasi tentang kesalahan yang terjadi, frekuensi pelaporan kejadian, perpindahan, dukungan organisasi untuk keselamatan pasien, respons nonpunitive terhadap kesalahan / respon tidak menghakimi pada kesalahan yang dilakukan, pembelajaran organisasionalpembelajaran, persepsi keseluruhan mengenai keselamatan, kepegawaian, supervisor / harapan manajer dan tindakan yang dilakukan untuk meningkatkan keselamatan pasien, kerjasama lintas unit, kerjasama antar unit / dalam unit. Konsep budaya keselamatan pasien menjadi poin penting dalam organisasi pelayanan keschatan, karena mempertahankan budaya keselamatan pasien maka budaya keselamatan pasien akan baik (Sheikh, Garcia, Jamal, \& Abdo, 2014). Hubungan antara kepuasan kerja perawat dan keselamatan pasien menjadi mudah untuk mewujudkan, karyawan yang puas dan bahagia ketika melakukan pekerjaannya tanpa terdistraksi oleh lingkungan kerja yang buruk maka akan menghasilkan kinerja yang baik, yang terkait dengan keselamatan pasien dan kinerja dalam hal lainnya (Asegid, Belachew, \& Yimam, 2014). Persepsi perawat mengenai otonomi di tempat kerja dan persepsi perawat mengenai prosedur keselamatan pasien merupakan faktor yang mempengaruhi kepuasan kerja perawat (Inoue, Karima, \& Harada, 2017). Keselamatan Pasien merupakan syarat untuk diterapkan di semua rumah sakit yang diakreditasi oleh Komisi Akreditasi Rumah Sakit. Maksud dari Sasaran Keselamatan Pasien adalah mendorong perbaikan spesifik untuk menunjang keselamatan pasien. Sasaran 
menyoroti bagian-bagian yang bermasalah dalam pelayanan kesehatan dan menjelaskan bukti serta solusi dari konsensus berbasis bukti dan keahlian atas permasalahan ini. Diakui bahwa desain sistem yang baik secara intrinsik adalah untuk memberikan pelayanan kesehatan yang aman dan bermutu.

\section{Tujuan :}

Untuk dapat menegtahui, mengerti dan memahami hubungan tingkat pengetahuan perawat dalam promosi dan evaluasi budaya keselamatan pasien.

\section{Metode:}

Artikel Ilmiah ini berdasarkan tinjauan sistematik dari beberapa artikel jurnal penelitian yang dipublikasi pada basis elektronik menggunakan metode tersearch dan analisis dari berbagai sumber seperti buku teks, buku referensi jurnal, dan e-book, dengan menggunakan Google Scholar,Portal Garuda dan Jurnal Keperawatan Indonesia. Yang berhubungan dengan hubungan tingkat pengetahuan perawat budaya keselamatan pasien, serta mengetahui impelementasi budaya pasien di rumah sakit. Dari berbagai sumber informasi digunakan untuk mengetahui pengaruh faktor-faktor yang berhubungan.

\section{Hasil:}

Mutu pelayanan yang berkualias dan dibarengi dengan jaminan patient safety yang tinggi akan menghasilkan citra rumah sakit yang baik dimata pasien sebagai konsumen rumah sakit. Nilai patient safety merupakan hal yang sangat penting untuk diterapkan dan ditanamkan pada setiap anggota organisasi, karena patient safety merupakan hal yang fundamental. Pemahaman yang baik terkait patient safety akan menjadikan setiap anggota organisasi mengetahui apa yang akan dilakukan. Perilaku tersebut pada akhirnya menjadi suatu implementasi yang tertanam dalam setiap anggota organisasi berupa perilaku Implementasi patient safety. Penerapan budaya keselamatan ada di tiga level, yaitu level individu, level manajemen dan level kebijakan. Ini berarti bahwa terciptanya budaya keselamatan memerlukan partisipasi dan tanggung jawab semua pihak yang berkepentingan dengan organisasi. Hal ini mencakup mulai dari penentuan kebijakan, pengaturan 
organisasi, hingga penerapan dalam operasi sehari-hari di lapangan.14 Department of Workplace Health and Safety Queensland mendefinisikan budaya keselamatan adalah budaya organisasi yang menempatkan tingkat kepentingan pada keyakinan keselamatan, nilai dan sikap, dan ini dimiliki oleh mayoritas orang didalam perusahaan atau tempat kerja. Suatu budaya keselamatan yang positif dapat menghasilkan kesehatan dan keselamatan kerja yang lebih baik dan performa organisasi.. Sesuai dengan penelitian yang dilakukan oleh Dewi (2010) bahwa umur mempengaruhi penerapan Patient Safety. Artinya, semakin tinggi umur perawat maka semakin tinggi penerapan Patient safety. Umur yang semakin tinggi diharapkan memiliki penerapan yang lebih tinggi pula karena memiliki pengetahuan yang luas, pengalaman yang banyak, dan pemahaman yang tinggi akan pentingnya menjaga mutu pelayanan. Perawat yang tidak menerapkan Patient Safety Identifikasi pasien merupakan perawat yang dominan tidak pernah mengikuti pelatihan Patient Safety. Sesuai dengan penelitian yang dilakukan oleh Utami (2011) bahwa pelatihan Patient Safety berhubungan dengan penerapan Patient Safety. Dimana tujuan dari pelatihan Patient Safety adalah untuk memberikan dan meningkatkan pengetahuan perawat terhadap segala aspek yang berhubungan dengan Patient safety agar dapat memberikan asuhan keperawatan sesuai dengan ketentuan yang berlaku. Aktor utama budaya keselamatan adalah masing-masing individu sebagai tenaga kerja dalam perusahaan yang secara sadar aktif mendukung tercapainya budaya keselamatan melalui gerak gerik atau tingkah lakunya sehari-hari bekerja. Menjalankan budaya keselamatan memang tidak mudah, karena perusahaan meliputi orang-orang dengan berbagai karakter dan latar belakang pula. Agar pelaksanaanyan maksimal, budaya keselamatan memiliki tiga prinsip utama, pertama, individu yang mendukung secara aktif menolak tindakan-tindakan yang membahayakan keselamatan. Kedua, individu harus memiliki alarm atau pengingat dalam dirinya, bahwa setiap perbuatannya akan memberikan dampak keselamatan bagi dirinya, orang lain dan perusahaan tempat ia bekerja. Ketiga, setiap invidu mengemban tanggung jawab keselamatan bagi dirinya maupun organisasi dan menjalankannya meskipun tanpa intervensi dari siapapun. 


\section{Pembahasan :}

Perawat adalah seseorang yang berperan dalam merawat atau memelihara, membantu dan melindungi seseorang karena sakit. Sebagai tenaga kesehatan, perawat memiliki sejumlah peran di dalam menjalankan tugasnya sesuai dengan hak dan kewenangan yang dimiliki. Peran perawat yang utama adalah sebagai pelaksana, pengelola, pendidik dan peneliti. Pengetahuan adalah fakta, keadaan atau kondisi tentang pengertian mencakup kombinasi dari kesadaran sederhana tentang fakta dan pemahaman tentang bagaimana fakta itu berkaitan satu sama lain). dengan teman sejawat, perawat berkewajiban melindungi klien dari tenaga Dalam kode etik keperawatan disebutkan bahwa perawat memiliki tanggung jawab agar senantiasa memelihara mutu pelayanan keperawatan yang tinggi disertai kejujuran profesional yang menerapkan pengetahuan serta ketrampilan keperawatan sesuai dengan kebutuhan klien. Dalam hubungannya kesehatan yang memberikan pelayanan kesehatan secara tidak kompeten, tidak etis dan ilegal. Rumah sakit harus mendidik pasien dan keluarganya tentang kewajiban dan tanggung jawab pasien dalam asuhan pasien. Kriteria dari Keselamatan dalam pemberian pelayanan dapat ditingkatkan dengan keterlibatan pasien yang merupakan partner dalam proses pelayanan. Karena itu, di Rumah Sakit harus ada sistem dan mekanisme mendidik pasien dan keluarganya tentang kewajiban dan tanggung jawab pasien dalam asuhan pasien. Dengan pendidikan tersebut diharapkan pasien dan keluarga dapat Memberikan informasi yang benar, jelas, lengkap dan jujur, mengetahui kewajiban dan tanggung jawab pasien dan keluarga, menga- jukan pertanyaan-pertanyaan untuk hal yang tidak dimengerti, memahami dan menerima konsekuensi pelayanan, mematuhi instruksi dan menghormati peraturan Rumah Sakit, memperlihatkan sikap menghormati dan tenggang rasa dan emenuhi kewajiban finansial yang disepakati. Rumah sakit menjamin kesinambungan pelayanan dan menjamin koordinasi antar tenaga dan antar unit pelayanan. Kriterianya yaitu Terdapat koordinasi pelayanan secara menyeluruh mulai dari saat pasien masuk, pemeriksaan, diagnosis, perencanaan pelayanan, tindakan pengobatan, rujukan dan saat pasien keluar dari Rumah Sakit, terdapat koordinasi pelayanan yang disesuaikan dengan kebutuhan pasien dan kelayakan sumber daya secara berkesinambungan sehingga pada seluruh tahap 
pelayanan transisi antar unit pelayanan dapat berjalan baik dan lancar, terdapat koordinasi pelayanan yang mencakup peningkatan komunikasi untuk memfasilitasi dukungan keluarga, pelayanan keperawatan, pelayanan sosial, konsultasi dan rujukan, pelayanan kesehatan primer dan tindak lanjut lainnya, terdapat komunikasi dan transfer informasi antar profesi kesehatan sehingga dapat tercapainya proses koordinasi tanpa hambatan, aman dan efektif. Standar rumah sakit harus mendesain proses baru atau memperbaiki proses yang ada, memonitor dan mengevaluasi kinerja melalui pengumpulan data, menganalisis secara intensif Kejadian Tidak Diharapkan, dan melakukan perubahan untuk meningkatkan kinerja serta keselamatan pasien. Kriteria dari Setiap Rumah sakit harus melakukan proses perancangan (desain) yang baik, mengacu pada visi, misi, dan tujuan Rumah sakit, kebutuhan pasien, petugas pelayanan kesehatan, kaidah klinis terkini, praktik bisnis yang sehat, dan faktor-faktor lain yang berpotensi risiko bagi pasien sesuai dengan "Tujuh Langkah Menuju Keselamatan Pasien Rumah Sakit", setiap Rumah Sakit harus melakukan pengumpulan data kinerja yang antara lain terkait dengan: pelaporan insiden, akreditasi, manajemen risiko, utilisasi, mutu pelayanan, keuangan, setiap Rumah Sakit harus melakukan evaluasi intensifterkait dengan semua Kejadian Tidak Diharapkan, dan secara proaktif melakukan evaluasi satu proses kasus risiko tinggi, setiap Rumah Sakit harus menggunakan semua data dan informasi hasil analisis untuk menentukan perubahan sistem yang diperlukan, agar kinerja dan keselamatan pasien terjamin. tingkat tertinggi dalam budaya keselamatan adalah tingkat generatif. Tingkat ini mengacu pada adanya motivasi intrinsik dalam individu sehingga terbentuk tingkah laku yang selalu didasarkan pada prinsip-prinsip keselamatan. Tingkat generatif inilah yang kemudian dibuat proses pencapaiannya dengan pendekatan program Heart and Minds. Terdapat 3 pilar utama untuk mencapai target budaya keselamatan yang generatif. Pertama, Proactive Invention, pada pilar ini, individu akan selalu proaktif dalam mengintervensi praktik-praktik yang dipandang mengabaikan faktor keselamatan. Tujuannya adalah untuk mempertahankan tingkat kecelakaan yang terjadi sangat minimal atau bahkan sampai pada titik nol. Kedua, Individual Qonsequences, yaitu individu harus menyadari bahwa setiap tingkah lakunya akan menghasilkan konsekuensi keselamatan bagi dirinya dan 
bagi orang lain. Oleh karena itu, prediksi-prediksi mengenai resiko bagi keselamatan sampai hal yang sekecil-kecilnya selalu harus dilakukan sebelum melakukan tindakan tertentu. Ketiga, Personal Responsibilities, pilar ketiga ini mengacu pada prinsip bahwa setiap individu mempunyai tanggung jawabnya masing-masing. Tanggung jawab ini harus dipegang dan dilaksanakan selalu. Ada hubungan komunikasi terhadap budaya keselamatan pasien, hasil penelitian ditemukan bahwa masih minimnya feedback yang diberikan tentang perubahan yang dilakukan berdasarkan laporan insiden kemudian staf mengemukakan bahwa tidak dapat berbicara dengan bebas apabila mereka melihat suatu hal yang dapat berdampak negatif pada perawatan pasien. Kegagalan komunikasi paling tinggi ditemui pada komunikasi lisan. Keselamatan pasien dapat ditingkatkan melalui komunikasi efektif, tepat waktu, akurat, lengkap, dan jelas, komunikasi antara pemberi pelayanan harus ditingkatkan, komunikasi dalam pelayanan kesehatan terjalin antara semua tim yang terlibat. Mendidik pasien dan keluarga Standarnya adalah rumah sakit harus mendidik pasien dan keluarganya tentang kewajiban dan tanggung jawab pasien dalam asuhan pasien. Keselamatan dalam pemberian pelayanan dapat ditingkatkan dengan keterlibatan pasien yang merupakan partner dalam proses pelayanan. Rumah sakit harus memiliki sistem dan mekanisme mendidik pasien dan keluarganya tentang kewajiban dan tanggung jawab pasien dalam asuhan pasien. Pemberian edukasi tersebut diharapkan pasien dan keluarga dapat:

a) Memberikan informasi yang benar, jelas, lengkap dan jujur.

b) Mengetahui kewajiban dan tanggung jawab pasien dan keluarga.

c) Mengajukan pertanyaan-pertanyaan untuk hal yang tidak dimengerti

d) Memahami dan menerima konsekuensi pelayanan.

e) Mematuhi instruksi dan menghormati peraturan rumah sakit.

f) Memperlihatkan sikap menghormati dan tenggang rasa.

g) Memenuhi kewajiban finansial yang disepakati.

Pengetahuan perawat tentang patient safety merupakan hal yang penting, karena jika pengetahuan perawat tentang patient safety kurang maka jelas ini akan berpengaruh terhadap kinerja perawat itu sendiri dalam penerapan patient safety 
di rumah sakit. Aplikasi pengetahuan dibidang kesehatan yakni hubungan antara fakta dan interpretasi informasi mengenai penyebab dan usaha preventif penyakit serta keterampilan dalam perbaikan kesehatan. Pengalaman yang telah dan sedang dialami seseorang akan membentuk dan mempengaruhi penghayatan seseorang terhadap stimulus, yang kemudian akan membentuk sikap positif atau negatif. Belajar dibutuhkan seseorang untuk mencapai tingkat kematangan diri. Proses belajar dapat dilakukan oleh karyawan yang dalam hal ini perawat, pada saat menjalankan tugasnya.

\section{Penutup :}

Terdapat hubungan antara tingkat pengetahuan perawwat dan praktek keselamatan pasien, diketahui pula bahwa semakin tinggi tingkat pengetahuan perawat tentang keselamatan pasien maka praktek keselamatan pasien dalam asuhan keperawatan semakin baik adalah benar. Hasil analisis hubungan antara tingkat pengetahuan dan praktek keselamatan pasien memiliki hubungan positif. Dengan diketahuinya bahwa tingkat pengetahuan sangat berpengaruh terhadap praktek keselamatan pasien maka perlu dilakukan perbaikan yang menuju pada peningkatan pengetahuan dan perbaikan praktek keselamatan pasien . Pihak rumah sakit dapat mengembangkan cara agar tingkat pengetahuan perawat semakin baik, dengan melakukan:

a) Pelatihan tentang keselamatan pasien secara berkala.

b) Pemasangan leaflet yang berisikan himbauan untuk melaksanakan praktek keselamatan pasien.

c) Melakukan supervisi atau pengawasan terhadap praktek keselamatan pasien dengan membentuk tim pengawasan di dalam rumah sakit dan pendidikan keperawatan diberikan kepada perawat agar lebih mengerti praktek asuhan keperawatan

Bagi perawat perlu meningkatkan pengetahuan tentang patient safety Sehingga dalam penerapannya akan semakin meningkatkan serta didapatkan hasil yang baik terutama dalam memberikan perawatan bagi pasien sehingga pasien mendapatkan 
haknya dalam pelayanan kesehatan yang aman dan nyaman dan mengurangi kejadian yang tidak diharapkan atau ktd.

\section{DAFTAR PUSTAKA}

Andayani, S. (2018). Penerapan Program Budaya Keselamatan Dalam Mendukung Kesehatan dan Keselamatan Kerja Pustakawan di Perpustakaan STTN Yogyakarta. Tesis : UIN Sunan Kalijaga.

Arini, T. (2018). Budaya Keselamatan Pasien Berbasis Pemberdayaan Strukturual Dengan Kepuasaan Kerja Perawat. Tesis: FKEP UNAIR.

Cahyono, A. (2015). Hubungan Karakteristik Dan Tingkat Pengetahuan Perawat Terhadap Pengelolaan Keselamatan Pasien DI Rumah Sakit. Jurnal Ilmiah WIDYA, 3(2), 97-102.

Ito, R. S. (2019). Hubungan Tingkat Perawat Tentang Indentifikasi Dalam Patient Safety Dengan Pelaksanaannya Di Ruang Rawat Inap RSUD SK Lerik Kupang. Skripsi: FKEP Stikes Hang Tuah Surabaya.

Lestari, W. (2013). Hubungan Pengetahuan Perawat Tentang Patienty Safety Dengan Penerapan Patient Safety Pada Pasien Stroke Di Rawat Inap RSU PKU MUHAMMADIYAH BANTUL. Naskah Publikasi : STIKES Aisyiyah Yogyakarta.

Muliana, A., Mappanganro, A. (2016). Hubungan Pengertahuan Dan Sikap Perawat Dalam Penerapan Patient Safety Goal Indentifikasi Pasien Di Rumah Sakit IBNU SINA-UMI Makkasar. Jurnal Ilmiah Kesehatan Diagnosis, 9(1), 117124.

Pratama, D. A. (2017). Hubungan Tingkat Pengrtahuan Tentang Penerapan Patient Safety Dengan Persepsi Penerapan Patient Safety Oleh Perawat Di RSUD dr. Soedirman Mangoen Soemarso Wonogiri. Tesis : FK UNDIP.

Rosyada, S. D. (2014). Gambaran Budaya Keselamatan Pasien Pada Perawat Unit Rawat Inap Kelas III Rumah Sakit Umum Daerah Pasar Rebo. Skripsi : FK UIN Syarif Hidayatullah Jakarta. 
Simamora, R. H., \& Fathi, A. (2019). The Influence Of Training Handover Based SBAR Communication For Improving Patients Safety. Indian journal of public health research \& development, 10(9), 1280-1285.

Setijayato, A. (2014). Pengaruh Pengetahuan Dan Sikap Perawat Terhadap Penerapan Standart Keselamatan Pasien Di Instalasi Perawatan Intensif RSID Dr. Moewardi. Tesis : UNS.

Sesrianty, V., Harahap, H.B., Resti, D. (2018). Hubungan Pengetahuan dan Supervision Dengan Penerapan Pengurangan Resiko Pasien Jatuh. Jurnal Kesehatan Medika Saintika, 11(1). 51-60.

Sumarni, (2017). Analisis Impelementasi Patient Safety Terkait Peningkatan Mutu Pelayanan Kesehatan Di Rumah Sakit. Jurnal Ners Dan Kebidanan Indonesia, 5(2), 91-99. 